\title{
Prenylated chromones and coumarins from the leaves of Billburttia capensoides Sales \& Hedge (Apiaceae)
}

Mahefarivo Andrianjakaniaina 1, Diano Lova Rakotondramanana 2, Paule Annécie Benatrehina 3, Carla Slebodnick 4, Léa Rasoanaivo 2, Rinasoambolanoro Rakotosaona 1, Harinantenaina Liva Rakotondraibe ${ }^{3}$, Richard Stephan Rakotonandrasana ${ }^{1}$ and Emile Vincent Rasamison 5,*

${ }^{1}$ National Center of Applied Pharmaceutical Research, B.P.Box 702, Antananarivo 101, Madagascar.

2 Laboratory of Natural Substances Chemistry and Biological Organic Chemistry, Faculty of Sciences, University of Antananarivo, B.P. Box 906, Antananarivo101, Madagascar.

${ }^{3}$ College of Pharmacy, Division of Medicinal Chemistry and Pharmacognosy, The Ohio State University, Columbus, $\mathrm{OH}$ 43210, USA.

${ }^{4}$ Department of Chemistry and Virginia Tech, Blacksburg, Virginia 24061-0212, USA.

${ }^{5}$ High Education Institute of Antsirabe-Vakinankaratra, University of Antananarivo, B.P. Box 906, Antananarivo101, Madagascar.

GSC Biological and Pharmaceutical Sciences, 2021, 16(02), 103-109

Publication history: Received on 07 July 2021; revised on 11 August 2021; accepted on 13 August 2021

Article DOI: https://doi.org/10.30574/gscbps.2021.16.2.0233

\begin{abstract}
Billburttia Sales \& Hedge is a new genus endemic to Madagascar, which belongs to the Apiaceae family and comprises of two species, namely Billburttia capensoides and B. vaginoides. The present work was undertaken in a view to explore secondary metabolites from the leaves of $B$. capensoides, contributing to have more knowledge on the chemical profile of this species. Liquid-liquid partition followed by chromatographic separation of its ethanolic extract led to the isolation of two new prenylated chromones, 2'R-hydroxy-7-O-methylallopeucenin and the known coumarins imperatorin and xanthotoxin. Their chemical structures were established on the basis of spectroscopic methods including nuclear magnetic resonance (NMR) and high resolution mass spectrometry, and by comparison with the reported data in the literature. The structure of the compound 3 was confirmed by single-crystal X-ray diffraction. This is the first report on the nonvolatile constituents of $B$. capensoides. The presence of imperatorin and xanthotoxin supported that the new endemic genus Billburttia belongs to the Apiaceae family. All these data may induce further research on this species in order to find new chemical entities with biological and chemotaxonomic interests.
\end{abstract}

Keywords: Billburttia capensoides; Apiaceae; Chemical constituents; Prenylated chromones; Coumarins

\section{Graphical abstract}

\footnotetext{
${ }^{*}$ Corresponding author: Emile Vincent Rasamison

High Education Institute of Antsirabe-Vakinankaratra, University of Antananarivo, B.P. Box 906, Antananarivo101, Madagascar. 


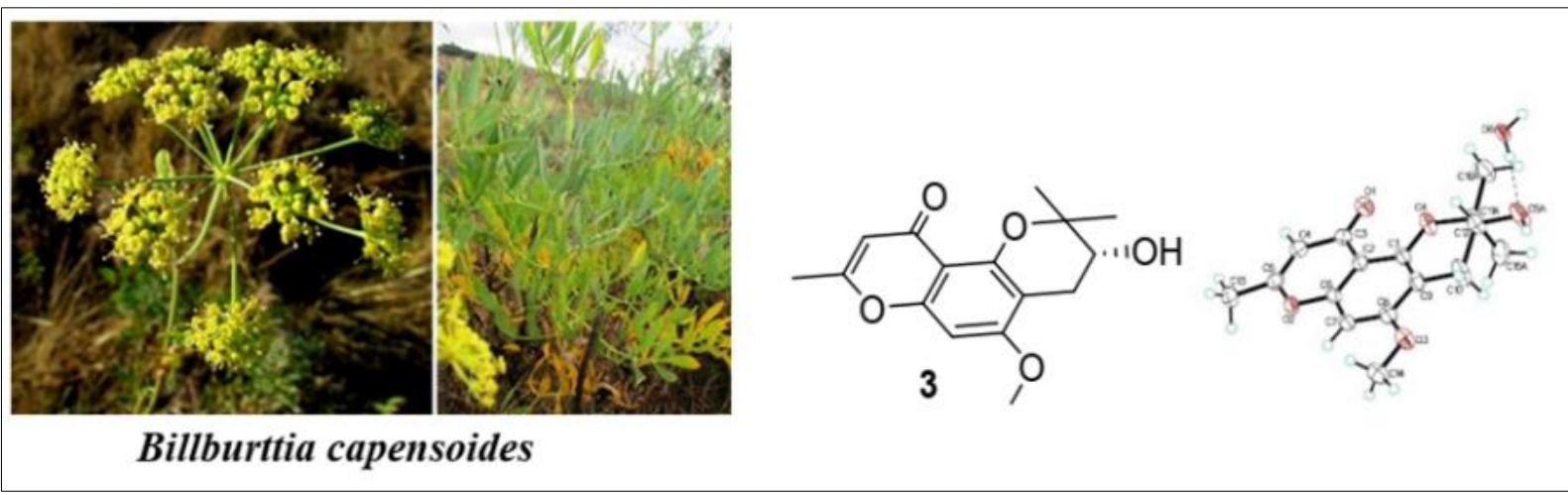

\section{Introduction}

Billburttia (Apiaceae) is a new endemic genus of Madagascar and comprises only two species, namely B. capensoides Sales \& Hedge and B. vaginoides S. \& H [1]. These two species were initially placed in the genus Peucedanum (Apiaceae) before being transferred into Billburttia [2]. The present report is focusing on B. capensoides which is a shrub of $2 \mathrm{~m}$ in height, encountered in the central part of Madagascar and locally known under the vernacular name Volotaratsitsina. The plant is traditionally used for the treatment of jaundice, convulsion and common cold [3]. The composition of the essential oils from the two Billburttia species has been previously reported with $p$-mentha-1,3,8-triene, terpinolene and dill apiole as the major components [4].

As a continuation of our study on medicinal plants endemic to Madagascar in a view to searching for new secondary metabolites and biologically active natural substances, we carried out a phytochemical investigation of the leaves of $B$. capensoides. Fractionation of the ethanol extract led to the isolation of three prenylated chromones (1-3) and the two coumarins ( 4 and 5). The isolation and structural identification of the two new chromone derivatives 1 and 2 as well as the X-ray analysis of 3 are described herein.

\section{Material and methods}

\subsection{Plant material}

The leaves of B. capensoides were collected in the region of Itasy, district of Arivonimamo, Commune of Manalalondo in the central part of Madagascar in September 2015. A voucher specimen (No. ST1494) is preserved in the Herbarium of the National Center of Applied Pharmaceutical Research, Antananarivo, Madagascar.

\subsection{Methods}

\subsubsection{General experimental procedures}

The NMR spectra were recorded on a Bruker Avance- 400 operating at $400 \mathrm{MHz}$ for ${ }^{1} \mathrm{H}$ and $100 \mathrm{MHz}$ for ${ }^{13} \mathrm{C}$. Preparative HPLC was performed using Shimadzu LC-20AB pumps coupled with a semi-preparative Purospher STAR $\mathrm{C}_{18}$ column (5 $\mu \mathrm{m}, 250 \times 10 \mathrm{~mm}$ ), a Shimadzu variable wavelength SPD-20A detector and a CBM-20A/20A lite Prominence system controller. Silica gel 60 (35-70 $\mu \mathrm{m}$, Fluka) was used for normal-phase flash column chromatography and silica gel 60 RP-18 (40 - $60 \mu \mathrm{m}$, EMD) for reversed-phase flash column chromatography. TLC analysis was carried out on Si gel 60 $\mathrm{F}_{254}$ (Merck) or reversed-phase $60 \mathrm{RP}-18 \mathrm{~F}_{254} \mathrm{~S}$ (EMD). All solvents were distilled before use.

\subsubsection{Extraction and Isolation}

The dried leaves of B. capensoides ( $440 \mathrm{~g}$ ) were ground into powder and extracted by maceration with EtOH (1.5 L) for 48 hours. After filtration and evaporation under reduced pressure of the solvent, the resulting ethanol extract (39.9 g) was taken in $\mathrm{MeOH}(250 \mathrm{~mL})$ and defatted with $n$-hexane $(3 \times 200 \mathrm{~mL})$. The methanol layer was evaporated to dryness and the residue was partitioned successively between chloroform and water, ethyl acetate and water, and $n$-butanol and water. Evaporation under reduced pressure of all the solvents used during this preliminary fractionation yielded $4.1 \mathrm{~g}$ of hexane-soluble, $10.1 \mathrm{~g}$ of chloroform-soluble, $2.6 \mathrm{~g}$ of ethyl acetate-soluble, $5.9 \mathrm{~g}$ of $n$-butanol-soluble (5.9 g) and $14 \mathrm{~g}$ of water-soluble fractions. 
Part of the chloroform-soluble fraction ( $4 \mathrm{~g}$ ) was applied to a silica gel flash column chromatography eluted with hexane/ ethyl acetate $(9: 1$ to $0: 1)$ then with ethyl acetate/MeOH (19:1 to 4:1) to give nine fractions (A - I). Imperatorin $(4,10.9 \mathrm{mg})$ crystallized from fraction B. Fraction C (1.2 g) was subjected to ODS flash chromatography eluted with $\mathrm{MeOH} / \mathrm{H}_{2} \mathrm{O}(1: 4$ to $9: 1)$ to afford xanthotoxin $(5,10.5 \mathrm{mg})$ and more imperatorin $(4,14.6 \mathrm{mg})$. Fraction $\mathrm{H}(1.1 \mathrm{~g})$ was further separated on flash ODS column eluted with $\mathrm{MeOH} / \mathrm{H}_{2} \mathrm{O}(1: 4$ to $4: 1)$ to afford five sub-fractions: $\mathrm{H}-1$ to $\mathrm{H}-5$. Compound 2 (12.4 mg) crystallized from sub-fraction H-3. Sub-fraction H-4 was purified on ODS HPLC eluting with $\mathrm{MeOH} / \mathrm{H}_{2} \mathrm{O}(11: 9)$ to furnish 1 (5.4 mg, $\left.\mathrm{t}_{\mathrm{R}}=27.7 \mathrm{~min}\right)$ and $3\left(1.8 \mathrm{mg}, \mathrm{t}_{\mathrm{R}}=47.3 \mathrm{~min}\right)$.

Compound 1 white solid; $[\alpha]^{23} \mathrm{D}+13.8$ (c 1.2 methanol); IR (NaCl) $v_{\max } 3418(\mathrm{OH}), 2925$ (aromatic methines), 1660 (conjugated carbonyl), 1586 (conjugated $\mathrm{C}=\mathrm{C}$ ) $\mathrm{cm}^{-1} .{ }^{1} \mathrm{H} \mathrm{NMR}_{\left(\mathrm{CDCl}_{3}, 400 \mathrm{MHz}\right)} \delta 6.44(1 \mathrm{H}, \mathrm{s}, \mathrm{H}-8), 6.09(1 \mathrm{H}, \mathrm{s}, \mathrm{H}-3), 3.93$ (3H, s, OMe-7), 3.59 (1H, ddd, J = 8.4 Hz, H-2'), 2.98 (1H, dd, J= 14, $2.4 \mathrm{~Hz}, \mathrm{H}-1^{\prime} \mathrm{a}$ ), 2.80 (dd, J = 14, 10.4, H-1'b), 2.39 (3H,

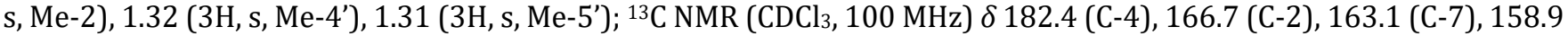
(C-5), 156.9 (C-8a), 110.4 (C-6), 108.9 (C-3), 105.2 (C-4a), 89.9 (C-8), 78.9 (C-2'), 72.9 (C-3'), 56.1 (OMe-7), 25.9 (C-1'), 25.0 (C-4'), 23.7 (C-5'), 20.5 (Me-2). [M+Na]+ m/z 331.1160 (calculated for $\mathrm{C}_{16} \mathrm{H}_{20} \mathrm{O}_{6} \mathrm{Na}^{+} 331.1152$ ).

Compound 2 colorless crystal; $[\alpha]^{23} \mathrm{D}+13.8$ (c 1.2 methanol); IR (NaCl) $v_{\max } 3418(\mathrm{OH}), 2925$ (aromatic methines), 1660 (conjugated carbonyl), 1586 (conjugated $\mathrm{C}=\mathrm{C}$ ) cm ${ }^{-1} .{ }^{1} \mathrm{H}$ NMR (CDCl $\left.3,400 \mathrm{MHz}\right) \delta 6.76(1 \mathrm{H}, \mathrm{s}, \mathrm{H}-3), 6.51(1 \mathrm{H}, \mathrm{s}, \mathrm{H}-5), 3.95$ (3H, s, OMe-7), 3.88 (1H, t, J = 5.2 Hz, H-2'), 2.91 (1H, dd, J = 17.6, 5.4 Hz, H-1'a), 2.72 (1H, dd, J = 17.6, 5.2 Hz, H-1'b), $2.41(3 \mathrm{H}, \mathrm{brd}, J=0.8 \mathrm{~Hz}, \mathrm{Me}-2), 1.46\left(3 \mathrm{H}, \mathrm{s}, \mathrm{Me}-4\right.$ '), $1.41\left(3 \mathrm{H}, \mathrm{s}, \mathrm{Me}-5\right.$ '); ${ }^{13} \mathrm{C} \mathrm{NMR}\left(\mathrm{CDCl}_{3}, 100 \mathrm{MHz}\right) \delta 177.7(\mathrm{C}-4), 166.0$ (C-2), 163.0 (C-6), 159.1 (C-8a), 153.7 (C-8), 109.7 (C-3), 106.1 (C-4a), 106.1 (C-7), 91.0 (C-5), 78.6 (C-3') 68.2 (C-2'), 56.1 (OMe-7), 26.1 (C-1'), 24.5 (C-4'), 21.7 (C-5'), 20.2 (Me-9). [M+Na] ${ }^{+} \mathrm{m} / z 313.1046$ (calculated for $\mathrm{C}_{16} \mathrm{H}_{18} \mathrm{O}_{5} \mathrm{Na}^{+}$ 313.1046).

Compound 3 Colorless crystal; $[\alpha]^{23} \mathrm{D}+42$ ( $c 0.1$ methanol); IR ( $\left.\mathrm{NaCl}\right) v_{\max } 3418(\mathrm{OH}), 2925$ (aromatic methines), 1660 (conjugated carbonyl), 1586 (conjugated $\mathrm{C}=\mathrm{C}$ ) $\mathrm{cm}^{-1}$. UV (MeOH) $\lambda_{\max }(\log \varepsilon) 202$ (4.45), $230 \mathrm{sh}(4.2), 250 \mathrm{sh}(4.02), 257$ (4.02), 290 (3.7). ${ }^{1} \mathrm{H} \mathrm{NMR}\left(\mathrm{CDCl}_{3}, 400 \mathrm{MHz}\right) \delta 6.43(1 \mathrm{H}, \mathrm{s}, \mathrm{H}-3), 6.19(1 \mathrm{H}, \mathrm{s}, \mathrm{H}-8), 3.92(3 \mathrm{H}, \mathrm{s}, 0 \mathrm{Me}-7), 3.86(1 \mathrm{H}, \mathrm{t}, J=5.2$, H-2'), 2.87 (1H, dd, J = 17.6, 5.2 Hz, H-1'a), 2.69 (1H, dd, J = 17.6, 5.2 Hz, H-1'b), 2.31 (3H, s, Me-2), 1.46 (3H, s, Me-4'), 1.42 (3H, s, Me-5'); ${ }^{13} \mathrm{C} \mathrm{NMR}\left(\mathrm{CDCl}_{3}, 100 \mathrm{MHz}\right) \delta 178.7$ (C-4), 165.0 (C-2), 160.1 (C-8a), 163.3 (C-7), 154.9 (C-5), 106.8 (C-4a), 112.7 (C-3), 106.8 (C-6), 92.4 (C-8), 79.5 (C-3'), 69.8 (C-2'), 57.3 (OMe-7), 27.6 (C-1'), 25.9 (C-4'), 23.1 (C-5'), 21.3 (Me-9). Crystal data of 3: $\mathrm{C}_{16} \mathrm{H}_{18} \mathrm{O}_{5}, \mathrm{M}=294.58$, monoclinic crystal system, crystal size $0.258 \times 0.165 \times 0.116 \mathrm{~mm}^{3}$, space group $I 2, a=6.63491(13) \AA, b=15.1675(2) \AA, c=14.2847(2) \AA, \alpha=90^{\circ}, \beta=94.61^{\circ}, \gamma=90^{\circ}, V=1432.88(4) \AA^{3}$, reflections collected 10289, parameters 251. The CIF file for 3 has been deposited in the Cambridge Crystallographic Data Centre [deposition number: CCDC 1957061].

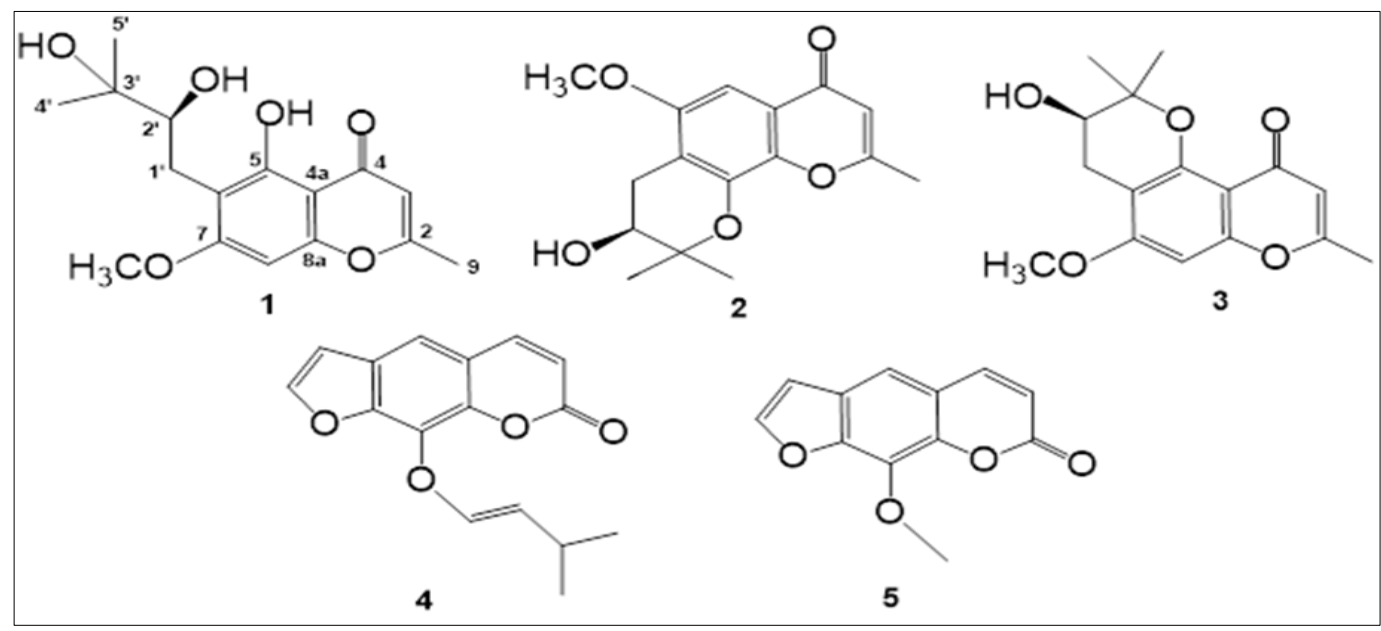

Figure 1 Structures of compounds 1-5 isolated from Billburttia capensoides

\section{Results and discussion}

The ethanol extract of the leaves from B. capensoides was liquid-liquid partitioned to give hexane-, chloroform-, butanoland water-soluble fractions. Fractionation of the chloroform-soluble part by a combination of chromatographic techniques, including normal phase silica gel and reversed phase silica gel (ODS $\mathrm{C}_{18}$ ) open columns, as well as reversed phase ODS-HPLC led to the isolation of two new compounds 1 and 2, 2'R-hydroxy-7-O-methylallopeucenin (3) and the 
two known coumarins imperatorin (4) and xanthotoxin (5) (Fig. 1). The structures of the known compounds 4 and 5 were identified by spectroscopic analyses including 1D and 2D NMR experiments and by comparison with data reported in the literature $[5,6,7,8]$.

Compound 1 was obtained as a white solid and its molecular formula was deduced to be $\mathrm{C}_{16} \mathrm{H}_{20} \mathrm{O}_{6}$ (requires seven degrees of unsaturation) by the observation of a sodiated molecular ion peak at $m / z 331.1160$ (calcd for $\mathrm{C}_{16} \mathrm{H}_{20} \mathrm{O}_{6} \mathrm{Na}^{+}$ 331.1152) in HRESIMS analysis. The IR spectrum showed the presence of conjugated carbonyl stretching at $1660 \mathrm{~cm}^{-1}$, aromatic and $\delta \delta$ olefinic absorption band at $2926 \mathrm{~cm}^{-1}$ and hydroxyl group at $3410 \mathrm{~cm}^{-1}$. The profile of its UV spectrum is very similar to those of previously described chromone [9]. The ${ }^{1} \mathrm{H}$ NMR spectrum showed signals consistent with the presence of a C-5 chelated hydroxyl group $(\delta 13.11, \mathrm{~s})$, one isolated aromatic proton $(\delta 6.44, \mathrm{~s}, \mathrm{H}-8)$, one methyl $(\delta 2.39$, s) attached to a double bond, one olefinic proton $(\delta 6.09, \mathrm{~s}, \mathrm{H}-3)$ and one methoxy group $(\delta 3.93, \mathrm{~s})$. The ${ }^{13} \mathrm{C} \mathrm{NMR}$ spectrum of 1 disclosed 16 carbon resonances consistent with a ketone carbonyl $(\delta 182.4, \mathrm{C}-4)$, four oxygenated $s p^{2}$ hybridized carbons $(\delta 166.7, \mathrm{C}-2 ; \delta 163.1, \mathrm{C}-7 ; \delta 158.9, \mathrm{C}-5 ; \delta 156.9, \mathrm{C}-8 \mathrm{a})$, two substituted $s p^{2}$ hybridized carbons $(\delta$ $110.4, \mathrm{C}-6 ; \delta 105.2, \mathrm{C}-4 \mathrm{a})$, two olefinic methines ( $\delta 89.9, \mathrm{C}-8 ; \delta 108.9, \mathrm{C}-3)$ and signals ascribable to a 2,3-dihydroxy-3methylbutyl unit as confirmed by HSQC and HMBC experiments. The basic skeleton of 1 was achieved by the interpretation of the HMBC spectrum starting from the olefinic proton $\mathrm{H}-3$ and aromatic one $\mathrm{H}-8$. The proton $\mathrm{H}-3(\delta$ $6.09, \mathrm{~s})$ correlated with the carbons at $\delta 20.5\left(\mathrm{CH}_{3}-2\right), 105.2(\mathrm{C}-4 \mathrm{a}), 166.7(\mathrm{C}-2)$, and the carbonyl carbon at $\delta 182.4(\mathrm{C}-$ $4)$. Similarly, the proton H-8 $(\delta 6.44, \mathrm{~s})$ correlated with the carbons at $\delta 105.2$ (C-4a), $110.4(\mathrm{C}-6), 156.9$ (C-8a) and 163.1 (C-7). In addition, strong $4 \mathrm{~J}$ coupling was observed between the proton $\mathrm{H}-8$ and the carbonyl carbon C-4, and between the proton $\mathrm{H}-3$ and the aromatic carbon C-5 $(\delta 158.9)$. From these NMR spectroscopic findings and by comparison with literature data $[10,11]$, a 2-methylchromene skeleton was established for 1 . The attachment of the 2,3-dihydroxy-3methylbutyl unit at C- 6 was evidenced by the HMBC cross-peaks between the methylene protons at $\delta 2.80$ and $2.98(\mathrm{H}-$ $\left.1^{\prime}\right)$ and the three aromatic carbons at $\delta 110.4$ (C-6), 158.9 (C-5), and 163.1 (C-7) (Fig. 2). The closest analogs are (2'S)perforatin $C(6)$ and its enantiomer (2'R)-perforatin $C(7)$, which have been reported from Harrisonia perforata (Rutaceae) [12] (Fig. 3). The NMR spectroscopic data of 1 are very similar to those of 6/7, except for the chemical shifts arising from the aromatic rings. Since $\mathrm{C}-2$ ' is the only chiral center in these molecules, the $(S)$-configuration was tentatively assigned to 1 based on the positive value of its optical rotation as that of 6 . Accordingly, the structure of 1 was proposed to be (2'S)-5-hydroxy-7-methoxy-2-methyl-6-(2,3-dihydroxy-3-methylbutyl)chromone.

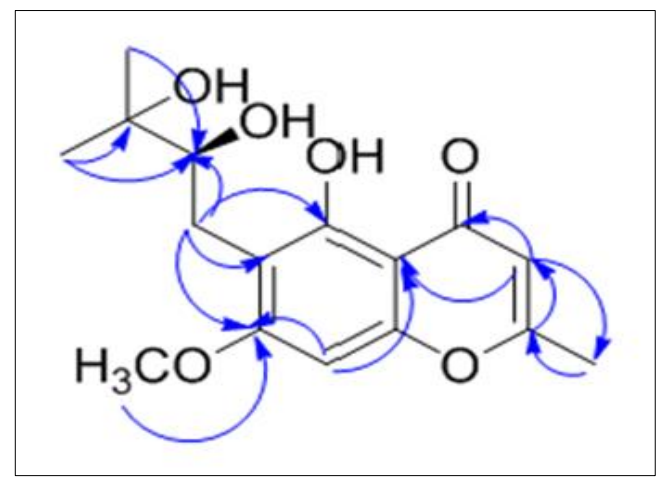

Figure 2 Key HMBC correlations observed in 1

Compound 2 was obtained as a white solid with a molecular formula of $\mathrm{C}_{16} \mathrm{H}_{18} \mathrm{O}_{5}$ as determined by the presence of a sodiated molecular ion peak at $\mathrm{m} / z 313.1046[\mathrm{M}+\mathrm{Na}]^{+}$(calculated for $\mathrm{C}_{16} \mathrm{H}_{18} \mathrm{O}_{5} \mathrm{Na}^{+}$313.1046)] in the HRESIMS spectrum. The IR spectrum showed the presence of hydroxyl and carbonyl groups. Comparison of the ${ }^{1} \mathrm{H}$ and ${ }^{13} \mathrm{C}$ NMR spectra of 2 with those of 1 revealed that it also possessed a 2-methylchromone skeleton, but without hydrogen-bonded hydroxyl group. This was supported by the correlations observed in the HMBC spectrum between the olefinic methine proton $(\mathrm{H}-3, \delta 6.76, \mathrm{~s})$ and the methyl $(\delta 20.2)$, aromatic carbon (C-4a, $\delta 106.1)$ and carbonyl C-4 carbon $(\delta 177.7)$, and by the 3 long-range correlations between the aromatic proton $\mathrm{H}-5(\delta 6.51, \mathrm{~s})$ and $\mathrm{C}-7(\delta 106.1), \mathrm{C}-8 \mathrm{a}(\delta 159.1)$ and $\mathrm{C}-4$ $(\delta$ 177.7) (Fig. 4). Moreover, the HMBC spectrum displayed correlations from the germinal methyl groups $(\delta 1.41$, s; $1.46, \mathrm{~s})$ to $\mathrm{C}-2^{\prime}(\delta 68.2)$ and $\mathrm{C}-3^{\prime}(\delta 78.6)$, and from the methylene protons $\mathrm{H}-1^{\prime}(\delta 2.72, \mathrm{dd}, J=17.6,5.2 \mathrm{~Hz}$ and $\delta 2.91$, $\mathrm{dd}, J=17.6,5.4 \mathrm{~Hz})$ to the oxygenated aromatic carbons $\mathrm{C}-6(\delta 163.0)$ and $\mathrm{C}-8(\delta 153.7)$. These data suggest that carbons C-3' and C-8 are linked by an ether function and the five carbons C-1', C-2', C-3', C-7 and C-8 form a 3',3'-dimethyldihydropyran ring. Complete assignment of the ${ }^{1} \mathrm{H}$ and ${ }^{13} \mathrm{C}$ signals of compound 2 was achieved by the interpretation of correlations observed in the HSQC and HMBC spectra. Two closely related compounds, (2'S)-2'-hydroxy-7-Omethylallopeucenin (8) and (2'S)-5-0-methylhamaudol (9), have been previously reported from Diplolophium buchananii of the Apiaceae family [13] (Fig. 3). The major difference in the gross chemical structures of the three 
compounds 2, 8 and 9 is the position of the dihydropyran ring on the 2-methylchromene skeleton. Regarding specifically the optical rotations of 8 and 9, the strong negative value for 8 becomes slightly positive for 9, while conserving the $\left(2^{\prime} S\right)$-configuration in both of them. Accordingly, the (2'S)-stereochemistry was tentatively ascribed to 2 based on the fairly positive value of its optical rotation. In light of the above results, the structure of 2 was established as depicted in Fig. 1.

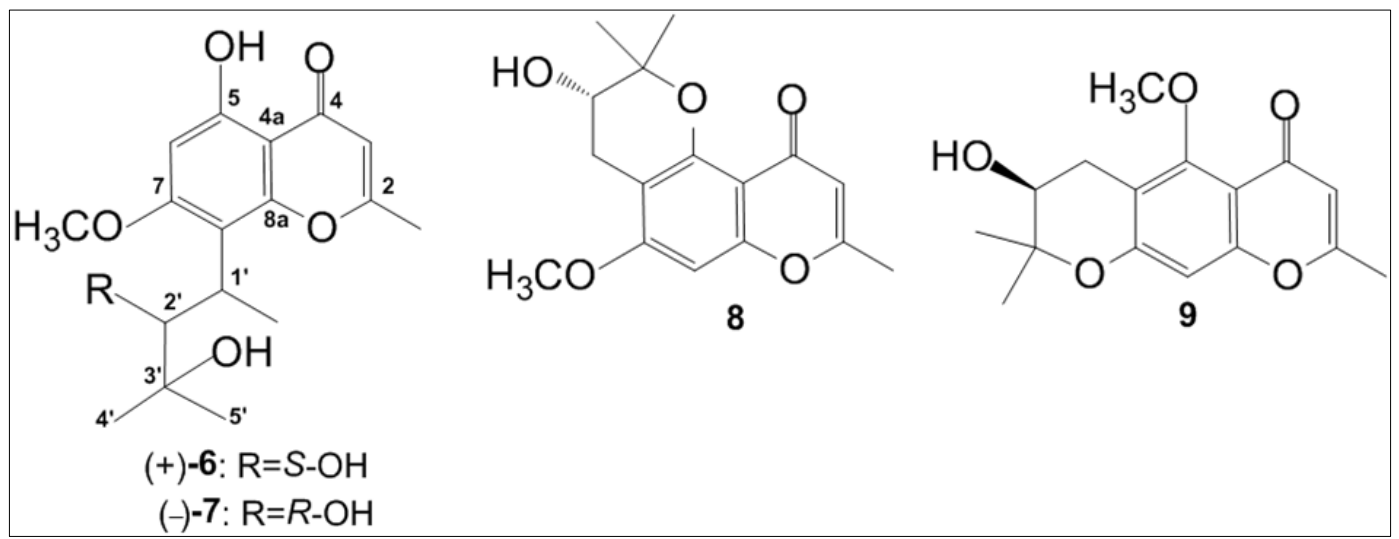

Figure 3 Structures of compounds 6-9

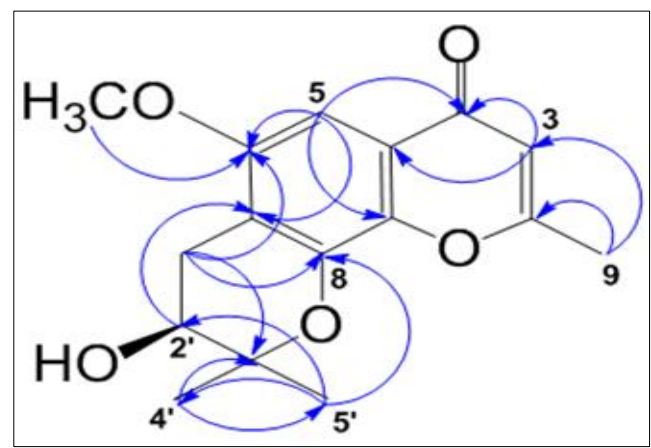

Figure 4 Key HMBC correlations observed in 2
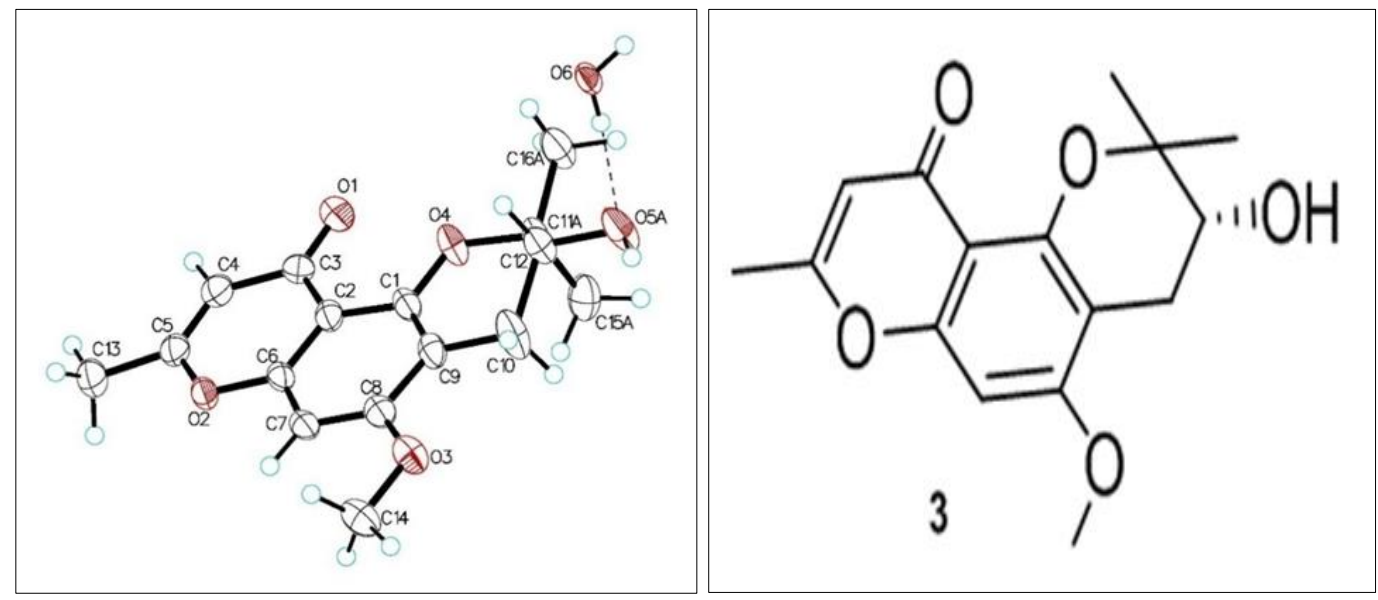

Figure 5 Anisotropic displacement ellipsoid drawing (50\% probability) of 3 
Compound 3 was obtained as a colorless crystal. Its NMR spectroscopic data were superimposable with those of (2'S)2'-hydroxy-7-O-methylallopeucenin (8) [13]. To confirm the proposed structure of 3, including the absolute configuration at C-2', a crystal structure was obtained via single-crystal X-ray diffraction (Fig. 5). As shown in the X-ray crystallographic data, the structure of 3 was enantiomeric to 2 'S-hydroxy-7- $O$-methylallopeucenin (8). The relative strong positive value of the optical rotation of $\mathbf{3}$ is in agreement with this result. Thus the structure of $\mathbf{3}$ was determined to be 2'R-hydroxy-7-O-methylallopeucenin (or 2' $R$-hydroxy-3',3',2-trimethyl-7-methoxy-3,4-dihydropyrano[2,3-f]10Hchromen-4-one).

Prenylated chromones have been reported to exhibit anti-HIV, antiproliferative and anti-inflammatory activities $[14,15]$. Coumarins have been considered as one of the major biochemical markers of the Apiaceae family.

\section{Conclusion}

The present study suggests that B. capensoides is a new source of prenylated chromones, as exemplified by the two novel compounds 1 and 2. Moreover, the isolation of the prenylated chromone $\mathbf{3}$ was described herein for the first time although it was established to be the $\left(2^{\prime} R\right)$-enantiomer of the reported 2 ' $S$-hydroxy-7-O-methylallopeucenin by X-ray crystallographic analysis. The presence of imperatorin (4) and xanthotoxin (5) in B. capensoides supported that the new endemic genus Billburttia belongs to the Apiaceae family. All the above data may induce further research on this species in order to find new chemical entities with biological and chemotaxonomic interests.

\section{Compliance with ethical standards}

\section{Acknowledgments}

The authors wish to thank the Ministry of High Education and Scientific Research in Madagascar for the funding of this research. The National Center of Applied Pharmaceutical Research, Antananarivo, Madagascar is acknowledged for making available the infrastructure and chemicals needed for the laboratory work. We are also thankful to the College of Pharmacy of the Ohio State University for giving the access to the instruments of NMR and Mass data collection.

\section{Disclosure of conflict of interest}

No competing financial interests to declare.

\section{References}

[1] Magee AR, Van Wyk BE, Tilney PM, Sales F, Hedge I, Downie SR. Billburttia. A new genus of Apiaceae (tribe Apieae) endemic to Madagascar. Plant Systematics and Evolution. 2009; 283: 237-245.

[2] Humbert JH. Contributions à l'étude de la Flore de Madagascar et des Comores. Fascicule 5. Notuae Systematicae. 1956; 15: 118-128.

[3] Rakotonandrasana SR, Oskolski AA, Tilney PM., Kotina EL, Van Wyk BE. The rediscovery of Billburttia vaginoides, with notes on the morphology, anatomy, traditional uses and conservation status of the genus Billburttia (Apieae, Apiaceae). Phytotaxa. 2017; 321: 265-276.

[4] Rakotonandrasana SR, Rabehaja DJR, Paoli M, Serra DR, Andrianjara C, Bighelli A, Ramanoelina PAR, Tomi F. Chemical composition of the essential oils from the aerial parts of two Malagasy endemic species (Apiaceae): Billburttia capensoides Sales \& Hedge and Billburttia vaginoides Sales \& Hedge. Natural Product Research. 2018; 33(8): 1200-1203.

[5] He F, Wang M, Gao M, Zhao M, Bai Y, Zhao C. Chemical composition and biological activities of Gerbera anandria. Molecules. 2014; 19: 4046-4057.

[6] Koziol E, Skalicka-Wozniak K. Imperatorin-pharmacological meaning and analytical clues: profound investigation. Phytochemistry Reviews. 2016; 15(4): 627-649.

[7] Marumoto S, Miyazawa M. Biotransformation of Bergapten and Xanthotoxin by Glomerella cingulata. Journal of Agriculture and Food Chemistry. 2010; 58(13): 7777-7781.

[8] Sigurdsson S, Jonsdottir S, Gudbjarnason S. Geographical variation of the furanocoumarin composition of the fruits of Icelandic Angelica archangelica. Zeitschrift für Naturforschung. C, Journal of biosciences. 2012; 67(1-2): 1-7. 
[9] Griffiths PJF, Ellis GP. Benzopyrones. VI. Ultraviolet absorption spectra of chromone and 2-substituted chromones. Spectrochimica Acta, Part A. 1972; 28(4): 707-713.

[10] Feng Y, Blunt JW, Cole ALJ, Munro MHG. The isolation of two new chromone derivatives from the New Zealand fungus Tolypocladium extinguens. Journal of Natural Products. 2002; 65(11): 1681-1682.

[11] Leonti M, Casu L, Solinas MN, Cottiglia F, Caboni, Floris C, Gertsch J, Saba AR. A chromone from Seseli praecox (Apiaceae). Natural Product Communications. 2010; 5(4): 551-554.

[12] Liu G, Zheng R.R, Liu ZW, Wang WJ, Li GQ, Fan CL, Zhang XQ, Ye WC, Che CT. Enantiomeric chromones from Harrisonia perforata. Phytochemistry Letters. 2014; 10: 295-299.

[13] Lemmich J. Monoterpene, chromone and coumarin glucosides of Diplolophium buchananii. Phytochemistry. 1995; 38(2): 427-432.

[14] Fu YH, Guo JM, Xie YT, Yu XM, Su QT, Qiang L, Kong L, Liu YP. Prenylated chromones from the fruits of Artocarpus heterophyllus and their potential anti-HIV-1 activities. Journal of Agriculture and Food Chemistry. 2020; 68(7): 2024-2030.

[15] Liu YP, Yu XM., Zhang W, Wang T, Jiang B, Tang HX, Su QT, Fu YH. Prenylated chromones and flavonoids from Artocarpus heterophyllus with their potential antiproliferative and anti-inflammatory activities. Bioorganic Chemistry. 2020; 101: 104030. 